\title{
RESPONSE
}

\section{More Stormy Weather or Sunny Ways? \\ A Forecast for Change by Prisoners of the Canadian Carceral State \\ Jarrod Shook and Bridget Mclnnis}

\section{INTRODUCTION}

Upon being elected, Prime Minister Justin Trudeau (2015) mandated the Minister of Justice and Attorney General of Canada Jody Wilson-Raybould to review criminal justice laws, policies, and practices enacted during the 2006-2015 period where successive Conservative federal governments were in power. With the change in government there has been some initial, albeit cautious, optimism that Prime Minister Trudeau will follow through on his professed commitment to "sunny ways" (e.g. O'Connor, 2015; Doob and Webster, 2016). This optimism is not unfounded. Anecdotally, editorial staff from the Journal of Prisoners on Prisons (JPP) are hearing that parole grant rates have improved. The newly appointed Correctional Investigator Ivan Zinger has also recently reported a "sharp decline" in the use of solitary confinement (Harris, 2017). Nevertheless, as this special issue of the JPP demonstrates, a storm rages on in Canadian federal penitentiaries and the prisoners who have been weathering it have a forecast for change.

As a prisoner-written, academically-oriented, and peer-reviewed nonprofit journal based upon the tradition of the penal press, the JPP brings the knowledge produced by prison writers together with academic arguments to enlighten public discourse about the current state of carceral institutions. As such, the editors of this special issue are of the belief that part of the Government of Canada's promised review of criminal justice laws, policies, and practices should involve direct input from prisoners who, having experienced recent penal reforms first-hand, are well-positioned to assess their impact upon their lives and what changes are needed moving forward.

To this end, the JPP undertook a Canada-wide consultation of its own to request that Canadian federal prisoners provide their observations regarding what has changed in the penitentiaries where they have served time during the last decade in relation to the Harper government's punishment agenda. We asked them not just what they think about those changes and how they have impacted their lives, but also what prisoners would like to see moving forward in terms of their main priorities for change and the types of social 
action those outside of prison walls could engage in to help address the challenges that presently characterize life in a federal penitentiary (see Appendix).

We mailed out sixty-nine letters to every federal penitentiary in Canada, accounting for the fact that many institutions confine prisoners at maximum-, medium-, and minimum-security levels all within the same compound. Moreover, we had to consider the fact that CSC now classifies prisoners into sub-groups and also incarcerates those deemed to be living with mental illness in their regional treatment centres. We also sent letters to 'healing lodges', which are classified as minimum-security penitentiaries.

The response to our callout was overwhelming. The breadth and depth of the response letters we received back from prisoners covering all of CSC's five regions, spoke prominently and thoughtfully to the many challenges that currently characterize life inside a federal penitentiary. What these letters convey to us is that imprisonment, independent of the Harper-era punishment agenda, is damaging, yet the laws, policies and practices instituted under the last three Conservative federal governments have impacted prisoners in all the more cruel ways - ways that both undermine honest attempts by prisoners to better themselves and ultimately put at risk their chances for successful re-integration into the community if given the chance. If the current government is serious about "rehabilitation and public safety" they would be wise to heed prisoner's reasonable calls for an opportunity to better themselves in spite of a system which, whether intended or not, works against their attempts to do so in many instances.

Taken on the whole, the letters we received from prisoners, which are included in the pages of this issue, comprise a comprehensive account of the impacts of the punishment agenda, along with pragmatic recommendations for change to immediately improve life inside federal penitentiaries. Despite a fairly wide range in the scope and interpretation of these impacts, along with the type of changes that prisoners would like to see moving forward, the ten most prevalent areas of concern and reform that emerged are as follows: sentencing, mental health, health care, food, prisoner pay, old age security, education and vocational training, case management and staff culture, parole and conditional release conditions, and pardons.

There were also several other issues identified by sub-groups of prisoners, which we address immediately following our overview of the Conservative punishment agenda that offers a snapshot of the context 
where an intensification in the pains of imprisonment was endured by the contributors in this volume.

\section{AN OVERVIEW OF THE CONSERVATIVE PUNISHMENT AGENDA}

The scholarly literature and government reports engaged with below provide us with an overview of what has been said by experts about reforms to laws, policies, and practices related to the federal penitentiary system under the previous government. While the body of work tended towards organizing this information chronologically and in relationship to the distinct electoral cycles in, which former Prime Minister Stephen Harper and his Conservative government were in a position to roll out their 'tough on crime' agenda (minority: 2006-2008, 2008-2011 and majority: 20112015), we have chosen to organize this information thematically.

\section{Laws}

In the legislative realm, we found that the academic community was particularly concerned with changes to the Criminal Code (Cook and Roesch, 2012), including the introduction of mandatory minimum sentences (Fournier-Ruggles, 2011), alterations to the criteria for an accused to access bail (Doob and Webster, 2015), a widening in the scope for 'dangerous offender' designations (Cook and Roesch, 2012), the creation of new offences for driving while impaired (Doob and Webster, 2016), and restrictions on the court's discretion to utilize alternatives to incarceration (Zinger, 2016). We also found concern on the part of the academic community regarding the elimination of additional credit that remanded prisoners received for time spent in pretrial custody (Doob and Webster, 2016), restrictions that were introduced on access to parole and statutory release such as the elimination of accelerated parole reviews (APR) (Parkes, 2014; Zinger, 2016), legislation that brings victims closer to the judicial and correctional decision making process (Cook and Roesch, 2012), and sweeping changes to the pardon system in Canada, now known as "record suspensions" (Doob and Webster, 2016). We further found that even though Canadian sentencing policy has historically been interpreted as one which valued "restraint", this fundamental principle went to the wayside under the Conservatives as evidence-based penal policy-making was dismissed and harsher punitive 
responses became the norm when new legislation was introduced (Doob and Webster, 2016).

On the whole, there seemed to be a consensus amongst those in the academic community that the legislative direction of the three Harper governments was one that would lead to a long-term overall increase in the penitentiary population who would now serve more time under harsher conditions, thus putting additional pressure on a system already strained to deliver on its mandate for public safety and rehabilitation. The pessimism expressed by academics regarding the Conservative legislative agenda concerning punishment was further enflamed by the fact that there was little by way of empirical support for their measures (Webster and Doob, 2015), as it was predicted that prisoners entering the system would ultimately come out the other side even less prepared for life in the community.

\section{Policies}

On the policy side, we found that one of the best sources regarding changes introduced as part of the previous government's punishment agenda were CSC's own departmental performance reports, which are a rich source of information regarding the implementation of laws, policies, and practices in the context of federal corrections. CSC highlights these as "achievements" and reports them as performance indicators. Significant policy changes related to this Dialogue can be organized according to three distinct themes: institutional security, cost-saving measures and accountability.

\section{Institutional Security}

During the Harper-era, CSC attempted to ramp-up its efforts to strengthen institutional security in a number of ways with new policies dedicated towards drug interdiction (Zinger, 2016), along with the alleged threat of "radicalized" prisoners (Monaghan, 2014) and other "security threat groups" (CSC, 2012, 2013, 2014, 2015, 2016). These included an expansion of the drug detector dog program (CSC, 2012), new search technologies (CSC, 2013), an increase in the frequency of searches (ibid), restrictions on access to "authorized items" (CSC, 2012; also see Parkes, 2014), increases in random urinalysis testing of prisoners (CSC, 2013), as well as the dedication of new resources towards securing perimeters, ION scan technology, and X-ray technology (CSC, 2015). Moreover, CSC developed new strategies in a stated effort to enhance the management of 
gangs, drugs and prisoners deemed to have been radicalized, including a National Radicalized Offender Threat Assessment in partnership with the Canadian Security Intelligence Services (CSIS), the Federal Bureau of Investigations (FBI), and the Federal Bureau of Prisons (FBOP) (CSC, 2012; also see Monaghan, 2014). As part of its focus on drug interdiction measures, along with alleged security threat groups and radicalized prisoners, CSC also made extensive revisions to its Commissioner's Directives to bolster the organization's power and authority to search prisoners, visitors, cells and vehicles, as well as intercept materials coming into institutions (CSC, 2013; also see Parkes, 2014).

The academic community anticipated that the increase in penitentiary population and length of time prisoners served before being released would necessarily bring about a strain on institutional resources, yet as Zinger (2016, p. 621) notes, "there always seems to be resources for more security measures and technologies" even in so-called times of fiscal austerity. This was a sentiment expressed frequently by scholars who seemed concerned that these additional security expenditures would take much needed resources away from rehabilitative programs and supports for prisoners (Cook and Roesch, 2012; Ricciardelli et al., 2014).

\section{Accountability}

As part of a wider agenda which emanated out of the Conservative government's partisan Roadmap to Strengthening Public Safety (Sampson et al., 2007; also see Jackson and Stewart, 2009), CSC also began placing a particular emphasis upon the subjective notion of "accountability" (CSC, 2012; also see Zinger, 2016). This entailed, as a matter of policy, bringing victims closer to the correctional decisionmaking process (CSC, 2012; Cook and Roesch, 2012), providing them with notifications, sending them information about prisoners and taking into consideration their concerns when making important decisions (CSC, 2015). CSC also began assessing accountability in the context of the 'correctional plan' (CSC, 2012), adding new procedures and methods touted as helping prisoners accept responsibility for their current behaviour and rehabilitation (CSC, 2013). This necessitated wide-reaching revisions to the case management policy framework that tied these factors to important decision-making processes like transfers to lower security institutions and access to parole (CSC, 2013). 
Interestingly, even front-line workers have problematized the accountability measures and have questioned not just the logic of this approach to case management, but also the degree to which it has strained relations with prisoners (Comack et al., 2015). Moreover, it was not lost on the academic community that measures of accountability, which "became a signature piece of the governments tough on crime message", were really just semantic justifications for austerity measures (Zinger, 2016, p. 216), many of which will be discussed below, and political maneuvering tactics and stratagems that the government relied upon to appeal to its base of support (Doob and Webster, 2015; Piché, 2015).

\section{Deficit-Reduction Measures}

CSC also introduced a number of cost-saving measures that resulted in drastic changes to a number of institutional policies related to services and programs designed to meet the needs of prisoners (CSC, 2012). These can be traced back to a $\$ 295$ million reduction in CSC's operating budget as part of the previous government's Deficit Reduction Action Plan (DRAP) (CSC, 2012). These policy-related changes included a significant modification to the policies and procedures in the management of food and "accommodation services" (CSC, 2014, 2015) and a substantial revision to its Commissioner's Directive on prisoner accommodations. As will be discussed below, for a time, this had resulted in an increase of the practice of double-bunking and what CSC termed "modernizing" of its food services department by introducing regional meal production centres that utilize "cook chill" technology (CSC, 2015). Moreover, CSC made significant changes to the way that spiritual services are delivered in institutions, including cut-backs and the enhanced privatization of chaplaincy services (CSC, 2013). Significantly, on the case management side, they also streamlined services that modified the way that parole officers conduct casework, thus reducing the number of face-to-face contacts they have with prisoners, which lengthened the wait times for correctional plan reviews (CSC, 2014).

These measures came to be among the "perverse effects of a tough on crime agenda on the lives or prisoners" (Zinger, 2016, p. 621; also see McElligott, 2009). The Office of the Correctional Investigator (OCI), in fact, has made these issues a centrepiece of its reporting annually and problematized them as conditions of confinement issues in serious need of redress (OCI, 2012; OCI, 2013; OCI, 2014; OCI, 2015). 


\section{Practices}

The above-mentioned changes to both legislation and CSC policies have had an impact on the everyday practices and culture within federal penitentiaries across Canada. Among these practices were a heightened use of segregation, double-bunking and the use of force. There were also practical changes more clearly associated with the pursuit of deficit-reduction.

\section{Segregation}

Though the length of time spent in segregation has been decreasing in recent years, the number of admissions per year had, up until recently, been increasing (OCI, 2015). This increasing number of admissions affects various sub-groups (i.e. Indigenous and Black prisoners), but not white prisoners (ibid). In the 2014-2015 fiscal year, there were 8,300 admissions to segregation (ibid). This practice continues to be used to handle what CSC would describe as 'difficult-to-manage' populations, including those who are deemed to be mentally ill, suicidal or engaging in self-injurious behaviours (ibid). Segregation has many consequences on prisoners. Prisoners with a history of segregation are more likely to be labeled as high-risk and high-needs, and are more likely to be identified as having low-motivation, low reintegration potential, and low accountability (ibid). Finally, administrative segregation has been and continues to be used to circumvent the limits of disciplinary segregation where prisoners can only be held for up to thirty days (ibid).

While it is recognized that there is a current trend towards reduced use of segregation (Harris, 2016), the academic community has long been concerned about this aspect of the "human cost" of the Conservative punishment agenda (Parkes, 2015; Piché and Major, 2015; Jackson, 2015; Kerr, 2015; Arbel, 2015). With an increased reliance upon punitive approaches, it was anticipated that the 'tough on crime' approach would result in an upsurge in such practices as segregation (Cook and Roesch, 2012). These concerns around segregation were tied in with legitimate fears about how this practice would affect the most vulnerable prisoners, those with "mental and physical health concerns", concerns which have become the impetus for the recent trend of a degree of restraint in the use of segregation as an administrative tool at the disposal of institutional authorities and now the subject of a class action lawsuit on the part of federal prisoners (Fine, 2016). 


\section{Crowding and Double-Bunking}

Canada's rate of imprisonment, in contrast with trends seen in many other jurisdictions (for example the United States) had remained relatively stable from about 1960 until 2006 where it sat at approximately 103 people per 100,000 (Doob and Webster, 2006, p. 331; Piché, 2015). Under successive Harper governments, however, imprisonment trended upwards and the Canadian prison population steadily increased at both the provincial and federal level, rising by 20 percent and 14 percent respectively (Comack et al., 2015, p. 3). This significant increase in prisoners was particularly borne by certain segments of the population, with a 77 percent increase in incarcerated women, 52 percent increase in the Indigenous prison population, and a 78 percent upsurge in the Black prison population (ibid).

While there was an uptick over the course of the decade, more recently the Canadian penitentiary population has been showing some signs of decreasing in recent years as the federal incarceration rates decreased by four percent between 2014-2015 and 2015-2016 (Reitano, 2016). In fact, the overall prison population decreased from 14,983 in 2011-2012 to 14,742 in 2015-2016 (OCI, 2012; Reitano, 2016). Despite this recent slight decrease in the prison population, however, problems with crowding remain. One example of the problematic effects of crowding in penitentiary, both past and present is the practice of double-bunking, which continues to be used as a population management strategy.

As of 2014, the national double-bunking rate stood at 20 percent, with the highest rates in the Prairies (OCI, 2014). While some observed tensions arising between double-bunked prisoners (see Shook, 2013), there has been increase in the number of assaults, lockdowns, searches, and use of force incidents (OCI, 2012, 2013). It should be noted, however, that as of 2016 the national double-bunking rate had been cut in half(CSC, 2016). Nevertheless, during the period of penal intensification under discussion here, substantial amendments were made to CSC's policy on double bunking. Formerly, CSC had endorsed the principle that "single occupancy accommodation is the most desirable and correctionally appropriate method of housing offenders" (as cited by Shook, 2013, p. 44). This principle belief, however, was struck from Commissioners Directive 550 Inmate Accommodation as the federal penitentiary population grew (CSC, 2013b). 
Research produced by CSC looking at the literature on crowding and double-bunking has suggested that the overall negative effect on prisoners and the institutional climate is negligible (Paquin-Marseille et al., 2012). Despite these state-produced findings, qualitative research with prisoners (Shook, 2013) and front-line workers (UCCO, 2011; Comack et al., 2015) suggests otherwise. Others have problematized this practice by drawing attention to the negative effects that it has upon an individual's "human spirit and human dignity" (Jackson and Stewart, 2009, p. 65). One need only look as far as any one of the annual reports of the OCI produced between 2006 to 2015 to find that the practice of double-bunking has been identified as a persistent problematic practice engaged in by CSC during the Harper-era.

\section{Use of Force}

In 2013-2014, the OCI investigated the largest number of use of force incidents in their history with the completion of 1,740 reviews (OCI, 2014). The evidence would suggest that there has been a heightened reliance on force to handle incidents, including those involving self-harm and suicidal behaviour (OCI, 2013, 2014). There has also been an increase in the use of inflammatory agents during these use of force incidents (OCI, 2014). Since 2010, correctional officers have been able to wear pepper spray around their belts, making it readily accessible during these use of force incidents (OCI, 2014). In 2013-2014, pepper spray was used in 60\% of these cases (OCI, 2014). Research conducted by Chricton and Ricciardelli (2016, p. 428) suggests that corrections under Harper has reshaped "the obligations of prison managers and in response the occupational role of CO's". The prison officers they interviewed acknowledged the fact that "punitive disciplinary methods" are "increasingly used in non-violent situations" even though they apparently "felt less harsh measures, such as verbal techniques of de-escalation, would suffice" (ibid, p. 435). This qualitative research runs parallel with the quantitative findings noted above as there has been an increased reliance upon security measures.

\section{Deficit-Reduction Measures Revisited}

As indicated above, in an effort to reduce spending, there have been budget cuts throughout federal penitentiaries that have impacted the day-to-day lives of prisoners. Prisoners are being charged more for phone calls and more deductions are being taken from their pay to finance their "food and 
accommodations" (OCI, 2013; also see Shook, 2015). Despite these new deductions, there has not been an increase in prisoner pay since the $1980 \mathrm{~s}$ (OCI, 2015). There have been cuts to social events and to library services, and prison farms were also being eliminated (OCI, 2013). Non-essential dental care was also removed, meaning that prisoners are only able to see a dentist in the case of an emergency (OCI, 2013). Finally, a new industrial food system has been introduced (the 'cook-chill system'), which has significantly impacted the diet and nutrition of prisoners (OCI, 2015).

McElligott (2009) and others predicted that such "no frills" measures would come to light as part of the implementation of the Roadmap to Strengthening Public Safety. Some questioned the fact that these cuts to programs, resources, and supports for prisoners ran parallel with an "overall increase in the Correctional Service of Canada's staff complement", which rose from 16,000 in 2006-2007 to 18,721 in 2014-2015 (Zinger, 2016). Also problematized was the fact that these changes coincided with heavy investments in both static and dynamic security measures, which the evidence has suggested do not yield commesurable additional public safety benefits, but may in fact serve to undermine them (ibid).

\section{AN OVERVIEW OF DAMAGING PENAL POLICIES AND PRACTICES UNDER THE HARPER GOVERNMENT FROM THE PERSPECTIVES OF PRISONERS}

\footnotetext{
Issues for Prisoners Pushed to the Margins

In his classic sociological study of a New Jersey state prison, Sykes (2007, p. 110) noted that "it might be argued that in reality there are as many prisons as there are prisoners - that each [prisoner] brings to the custodial institution [their] own needs and [their] own background and each [prisoner] takes away from the prison [their] own interpretation of life within the walls". Accepting Sykes claim that not all aspects of the experience of incarceration are universal, we recognized the importance of moving beyond issues that were widely cited by Canadian federal prisoners to also consider problems that appeared to disproportionately impact minorities incarcerated by CSC. Not wanting to overlook the latter, below we account for some of these concerns as issues of those pushed to the margins before addressing the most frequently cited themes.
} 


\section{Indigenous Peoples}

Over the ten-year period under review here there was a dramatic increase in both the Black and Indigenous federal penitentiary population (Zinger, 2016). The Black penitentiary population has increased by 78 percent and the Aboriginal prison population has seen an increase of 52 percent (Comack et al., 2015 p.3). This increase for both groups occurred in spite of longstanding criticisms regarding their mass incarceration as compared to the population of white federal prisoners, whose incarceration rates have been on the decline (OCI, 2013).

Prisoners themselves problematized these trends. For instance, a group of Anonymous Prisoners held in Fraser Valley Institution indicated to us that in addition to the population "fast becoming increasingly Indigenous" that "The ladies that remain in max now feel they are not having their spiritual needs met by the Elder that is in the position to assist them". They further described a process that seems to be related to a high turnover rate for Elders in the system. While not identifying themselves as Indigenous in their paper, Rachel Fayter and Sherry Payne of Grand Valley Institution also brought to our attention the fact cultural events, like the Annual Pow Wow, that are prescribed for Indigenous peoples to maintain linkages with their cultures have been "cancelled without reason and without any communication to prisoners". Anonymous Prisoner 15, who is Indigenous and held at Saskatchewan Penitentiary, has spent two decades in the penitentiary system and recently underwent major surgery to remove a tumour after being diagnosed with cancer described to us a similar difficulty in staying connected to his culture. After being approved for "cultural escorted passes" and completing several successful ETAs, he indicated how the Harper government brought about policy changes requiring prisoners serving a life sentence to appear before the PBC to apply for and obtain passes. He described having "dealt with my childhood trauma, my residential school abuse issues", while "waiting for almost two years for approval to go on passes" to continue his cultural ETAs.

Another prisoner held in Bath Institution indicated to us that Gladue sentencing principles, which are legally required to be considered in correctional decision-making processes that have a bearing on an individual's liberty are not being followed. This prisoner asks that the current government "review all policies that the previous government installed that had an effect on and consequently engulfed First Nations people". 
We received only a single response from an Inuit prisoner who described to us feelings of dislocation and the difficulty of maintaining family ties while incarcerated and the undue hardship brought upon family members who wish to maintain contact with their loved ones while incarcerated so far away from home. While we problematize his recommendation that "the federal government start considering to build a federal penitentiary" in Nunavut as its implementation would perpetuate the mass incarceration of Indigenous peoples, we appreciate why this prisoner would see this as a solution at a moment when the federal government has failed to deal with past and on-going destructive colonial relations (Monchalin, 2016; also see Martel et al., 2011).

\section{Black Prisoners}

We received one piece from a prisoner who identified themselves as being Black. Michael Leblanc at Dorchester Penitentiary provided a lengthy and thoughtful submission which spoke with a great deal of clarity to the problem of systemic racism. His analysis suggested that "Many minority prisoners are warehoused in our Canadian penitentiaries" receiving "harsher sentences" due to discrimination experienced when trying to obtain and maintain parole. He further described to us, as did others who touched upon issues related to Indigenous prisoners, "the importance for a minority to stay connected to one's culture and customs". As "there are cultural needs and traditions that are not being observed" he calls for a "cultural liaison to represent these ongoing human rights abuses", while also recommending that an ethno-cultural advisory representative be the liaison between racialized prisoners and government.

\section{Criminalized and Incarcerated Women}

We were grateful to be in receipt of several responses from women across the country who spoke eloquently and passionately to issues that are unique to them. The content of their contributions reveals shocking and appalling conditions of confinement for federally sentenced women. For instance, Rachel Fayter and Sherry Payne of Grand Valley Institution describe a culture of debasement towards women on the part of the guards where:

It is rare that a guard treats us with respect or dignity. They demean us, lie, make accusations and assumptions, tease us, restrict our choices, belittle 
us, swear and call us names. For example, guards have made fun of what clothing women wear, our make-up, our weight and how much junk food we purchase at canteen.

Another criminalized woman, Stephanie Deschene, held in Fraser Valley Institution described to us an experience of similarly poor treatment in the hands of the state. She arrived at the facility in maximum-security thirtyfour weeks pregnant, describing that the decision making regarding her institutional placement was, in part, paternalistic as she was accused of continuing to remain "in an abusive relationship, of which my baby's father was the aggressor". She further described the insensitivity shown to her on the part of the state following her giving birth to her son, when the very next day she was "shackled and cuffed" and not allowed to "breastfeed, hold and cuddle" her newborn son safely. This uncompassionate treatment continued upon her return from the hospital where the institutional security climate dictated that she would not be permitted to provide breast milk for her son due to the potential for "contamination".

Given the unique circumstances of female prisoners who have become pregnant before or during their incarceration, as well as those who have very young children, CSC had set up a "Mother-Child Program". Rachel Fayter and Sherry Payne described this as an initiative that "enabled women to live with their young children, ages five and under in a cottage designated as the mother-child unit located on the general compound". This program, which served, in large to maintain the bond between mother and child was scaledback under the Conservative government. Thus, the visiting room became the only place where some mothers could see their child. Rachel Fayter and Sherry Payne argue "is not a conducive location for a mother to bond with her child". Moreover, they note that in addition to the overarching security atmosphere imposed upon prisoners and their loved ones, "women have been denied the opportunity to hold their baby, breast feed and change diapers".

Another problem cited by the women who contributed to this project is the lack of halfway houses for women. For instance, those incarcerated in Ontario described women waiting months for a bed and being forced to live "hours from their community when released on day-parole". Such neglectful treatment shown towards women is an inequity that must be addressed. Incarcerated women are entitled to an equal benefit of accessing conditional release into a community of their choosing where they can remain close to 
their family and support systems. To do otherwise is discriminatory and sets them up for failure.

\section{LGBTQ Prisoners}

We received one submission that spoke to issues that LGBTQ prisoners face while incarcerated and the impact that recent penal intensification has had upon their lives. Rachel Fayter and Sherry Payne observe that the "LGBTQ community at GVI feel they are not accepted as individuals and especially not as a community". They describe an atmosphere where there is a prohibition on same-sex relationships that are deemed unacceptable by the guards. Moreover, it was noted that "An individual's partner is often mentioned in paperwork" and "Women in relationships have not been supported for parole due to their relationship and their partner of choice. Same-sex couples are also not permitted to have Private Family Visits together". What is being described above are human rights violation in need of serious redress. Prisoners do not forfeit their human rights at the gate of the penitentairy and are entitled to being protected from discrimination on the grounds of their sexual orientation.

\section{Elderly Prisoners}

While there is not a standard definition of what it means to be "elderly", for the purposes of our analysis we have chosen to follow the guidance of the Office of the Correctional Investigator, which identifies those aged 50 and older as being elderly (OCI, 2015). This is to recognize also that men and women behind the walls may age physically faster than their chronological age due to a variety of factors up to, and including, substandard health care and poor diets in addition to the stress and the punishment of body and mind that comes with serving a prison sentence (OCI, 2015).

We received several responses from elderly prisoners who shared experiences of incarceration that highlight how penitentiaries are particularly punishing for the elderly. For instance, a groups of Anonymous Prisoners held in Fraser Valley Institution describe a "lack of approach towards dementia and elderly care", adding that "We have a number of older ladies and they are not respected in that manner". Moreover, Anonymous Prisoner 8 of Beaver Creek Institution discusses the circumstances of elderly prisoners who are unable to work for health reasons, infirmities, and the like. Thus, they find it difficult to meet financial demands and purchase 
"non-essential health care items". A number of prisoners who wrote to us expressed their frustration with the government's decision to remove access to old age pensions for prisoners aged sixty-five and over. In fact, this was a frequently cited theme, which will be discussed in greater detail below.

Despite the pessimism expressed on behalf of elderly prisoners, we recognize a certain resilience and courage on their part. For instance, one elderly prisoner who chose to remain anonymous stated in a letter to us: "I am writing this document knowing that I have a parole hearing coming soon. I have been advised my freedom could be jeopardized by my writing this document to you. I am an elderly man and will not be victimized by fear and intimidation, and bullying that is commonly used by CSC personnel".

\section{Most Commonly Cited Issues}

As we undertook an analysis of letters that we received from prisoners across the country describing the impact upon their lives of the Harperera 'tough on crime' agenda, several recurring themes emerged from their responses. Below, is a summary of the most commonly cited issues that prisoners described to us and their reasonable forecast for change moving forward.

\section{Sentencing}

Under the Harper government, new mandatory minimum penalties (MMPs) were added to the Criminal Code. There are now over one hundred offences in the Criminal Code and the Controlled Drugs and Substances Act that carry MMPs (Eliot and Glynes, 2016). These MMPs can be applied in a variety of situations, including with drug offences and those who have been previously convicted (ibid). The use of MMPs, or sentencing in general, was mentioned throughout several letters from prisoners as an area requiring change.

According to Hyper A'Hern, MMPs take away judicial discretion by removing the judge's ability to choose a sentence that he or she deems fair and proportionate. This prisoner believes that this type of sentencing leaves judges with no other option but to impose a harsh sentence:

We are sending a mixed message to the public by binding judges to these minimums. We are saying to trust the courts with applying the law, while at the same time undermining the judicial system by not allowing a judge to impose the sentence they deem adequate. 
Many prisoners also mentioned that MMPs do not have a deterrent effect and that imposing harsher punishments does not reduce crime: "Empirical data shows that longer sentences do not make the public safer and only serve to make harder criminals who will eventually be released into society" (Trevor Bell held in Mission Institution). It was also noted by prisoners that there are many people in penitentiaries who do not need to be there and that serving time will likely make them more prone to commit new offences upon release. It was suggested that a review of current MMPs is needed and that alternatives, including restorative justice, should be more widely available to better promote rehabilitation and the repair of harm. Anonymous of Grand Valley Institution for Women concludes that a more compassionate approach is in order, one that includes "a close examination of the conditions that contributed their acts where relevant, including childhood abuse and suffering. These individuals need love, self-care and inner healing".

Another suggestion for change was to diver some people from the federal penitentiary system altogether: "Rather than mandatory minimum sentences, our justice system needs to consider alternative options. Persons who have not committed violent crime would be better off being referred to mental health, addiction or similar services as required" (1417 held in Riverbend Institution). It is evident when reading through prisoners' responses that they believe that the current sentencing system is broken and ineffective, and that far-reaching changes must be implemented.

\section{Mental Health}

Mental health care was identified as a central priority for federal prisoners. Stephanie Deschene held in Fraser Valley Institution noted that mental health personnel are understaffed, leading to long wait lists and a lack of timely access to necessary services: "Women who are trying to work past trauma and create healthy outlets are told they will be put on a waitlist. Should we not be preventing suicidal thoughts and actions not treating them once they happen?" Due to a lack of available staff, Trevor Bell held in Mission Institution argues that prisoners' mental health needs are only addressed in emergency situations:

Unless an individual is suicidal or engaging in acts of self-harm, they are likely to receive absolutely no treatment whatsoever. The Harper 
government repeatedly cut funding to the correctional system, allocating little to mental health in general, yet the presence of those living with mental health issues within penitentiaries is a pressing issue.

When individuals who are living with mental health issues while incarcerated are able to access psychological services, many prisoners who wrote to us described a scenario where rather than receiving therapeutic treatment they are simply medicated. This was described to us by both men and women. Michael Leblanc held in Dorchester Institution, referencing a study on the prevalence of psychotropic medications being offered to prisoners, states that "These medications are being prescribed to candy-coat the real issues of a prisoner's state of mind, rather than providing access to counselling and treatment". His position is that the "overmedication of federal prisoners must change, so that more resources can be dedicated to counselling". Yet even when prisoners are able to access such services, Rachel Fayter and Sherry Payne remind us that "since psychologists are employed CSC staff, women do not feel comfortable sharing their feelings and struggles based on the fear that what they say will end up in their paperwork", thus affecting "security ratings, temporary absences and parole". They recommend that "CSC return to hiring external social workers on contract to work with women in distress and those living with mental health issues, rather than CSC-employed psychologists".

Several prisoners also noted that prisons are not ideal environments for those suffering from mental illness and that being in prison can exacerbate their symptoms: "As a person suffering from PTSD, I am forced to engage in an environment that is significantly more prone to aggression and violence to the detriment of my emotional well-being, with the potential of undermining the efforts made in this area" (Anonymous Prisoner 20 held in Mission Institution).

It was also noted that prisoners may be required to participate in counselling sessions as part of their correctional plan, but they are unable to meet this requirement due to long wait periods and understaffing. For this reason, it was also suggested that more psychologists need to be hired to improve access to mental health services and to allow for more preventative and proactive care.

A final suggestion that was given related to mental health was to allow prisoners to have more contact with the outside world through volunteer 
programs. Such contact would be a way to improve mental health by decreasing feelings of isolation and solitude: "We can address this area [mental health] not by necessarily throwing more money at it, but by including our stakeholders - the community - through the promotion of outside volunteer participation, making our penitentiary walls more permeable" (Anonymous Prisoner 12 held in Beaver Creek Institution).

\section{Health Care}

The health of prisoners is not often considered a priority for the federal government despite high levels of chronic illnesses and infectious diseases amongst prisoners (OCI, 2016). For the prisoners who wrote to us, however, health care issues were a priority. Joe Convict held in Mission Institution draws our attention to the fact that the principle of equivalence is not being followed. He notes, "We are supposed to be receiving health care on par with citizens out in the community, but this is a fallacy". He further describes a situation where "there is an issue with the privatization of health care in that prisoners are getting substandard treatment and care. Prisoners are left in pain and denied the necessary treatment such as surgery or pain management programs available to persons out in the community". Other prisoners who wrote to us, including a group of Anonymous Prisoners at Kent Institution who drew a link between their physical health and the quality and portions of food that are provided to them, stating that "Approximately $20 \%$ of the penitentiary population here suffers severe digestive problems due to the food forced upon us, which has led to "bloody anal discharge, bloody stool, lower intestinal cramping and bloating, constipation and diarrhea, as well as stomach pains". Alarmingly, they describe prisoners seeking "help from outside health care staff hoping to receive food that does not hurt us and instead they receive medication that, at best, reduces the problems minimally".

Another issue described to us that has occurred with regards to health care is the removal of preventative dental treatment (ibid). Prisoners are only able to see a dentist in the case of an emergency. Preventative medical treatment in general is non-existent in penitentiaries, which, according to prisoners, is costing corrections more money in the long-run. Rachel Fayter and Sherry Payne of Grand Valley Institution state that "It can take weeks or months to see a doctor or dentist, even for antibiotics or a common cold or flu. The dentist at GVI specializes in extracting teeth and prefers pulling a 
tooth to providing a filling. There are no teeth cleaning or preventative care appointments available".

Prisoners are frustrated that they are not given the tools or opportunities to take their health into their own hands:

Before prison, I was in great health and took care of myself, but how are we to take care of ourselves when we are not given the opportunities or resources? I have had a tooth ache for the last three months and I am told, once again, that I will have to wait due to the lack of funding. I have become a burden on society with my many ailments that continue to grow and get worse over time.

- Anonymous Prisoner 3 held in Fraser Valley Institution.

Similar to the problems prisoners noted with respect to mental health care in penitentiaries, health care professionals are understaffed, leading to long wait-times and service provision largely limited to emergency situations. When treatment is given, in the domain of mental health, as is indicated above it is often limited to the prescription of medications as opposed to addressing the underlying causes of the illness: "and all the doctors seem willing to commit to in terms of care is prescribing an assortment of pills, including for mental health issues - simple zombification" (Anonymous Prisoner 19 held in Drumheller Institution). Exacerbating the situation is the fact that prisoners who speak out about their health concerns are treated with suspicion by healthcare staff, instead of compassion.

When discussing health care, most prisoners stated that better access to doctors is required, along with the hiring of more health professionals and enhanced provision of preventative services. It was also noted that prisoners often do not have a choice in their treatment plan (i.e. are simply prescribed a certain medication, which they are told to take regularly). Prisoners mentioned that it would be beneficial for them to be included in decisions about their health.

\section{Food}

As indicated in a previous section, one of the most common issues raised by prisoners was the poor quality of food. Anonymous Prisoner 12 held in Beaver Creek Institution described to us the new centralized food services model and "cook chill" technology: "The meal is prepared at a central site, 
packaged, frozen and shipped to the receiving institution. The institution then reheats the meal which is served to the prisoners". He goes on to state that under the old policy, "each institution had its own kitchen where staff and prisoners worked together" and "prisoners learned valuable skills that could easily be transferred to the community through the example set out by staff. They learned alternative ways of proper comportment".

This new policy, however, which was introduced as part of the previous government's cost-saving initiative, has been described as one where the quality and portions of food provided to prisoners has declined to such a degree that some prisoners have begun refusing to eat at all (CSC, 2015). Ronald Small held in Mission Institution describes having "witnessed the kitchen staff hanging their heads in shame because of what they are forced to serve us", he goes on to state that "you will find that the waste of food being thrown out is extremely high, which converts to wasted tax-payer's money". On a related noted, Anonymous Prisoner 17 held in Drumheller Institution states the following:

I have heard many guys complaining about going to sleep hungry. Less money to spend in the canteen, along with the poor quality and quantity of food serviced in kitchen, has led to short tempers with violence erupting from individuals being hungry. This has increased the number of guys being muscled for their canteen or "taxed".

This analysis highlights the relationship between the quality and portions of food, and the institutional climate for violence and other incidents which rose sharply during the Harper-era (OCI, 2012, 2013). To Trevor Bell held in Mission Institution this is "It is truly unconscionable in this day and age that we have reverted back to a time where prisoners are provided with only enough food to barely keep them alive - not healthy, just alive". Hyper A'Hern described the current situation like this:

I have also thrown up immediately after eating and as of now I eat almost exclusively bread, which consists of approximately $40 \%$ to $50 \%$ of our daily calorie intake. I do not need to express what this kind of malnutrition practice can do to a human body. We get fatter, while at the same time being malnourished. There are other animals in the animal kingdom that we do this to as well and their back fat makes a great burger taste better. 
Given what has been described above, it should come as no surprise that for many prisoners there was widespread agreement that food in prison was among the "highest priority" (Simon Chow held in Mission Institution). The proposals that we received from prisoners with respect to food services are simple: "The central feeding system must stop. Prisoners are human beings and should be treated as such" (T.B. held in Port-Cartier Institution). Trevor Bell, held in Mission Institution, echoed this sentiment with his proposal for "an immediate review of this entire program needs to be undertaken with a projected cancellation and reversion to the prior model of individual institutional food provision".

\section{Prisoner Pay and Purchasing}

Another concern that was high on the list of priorities for prisoners was their pay for the work that they do in the institution that contributes to the operation and maintenance of the penitentiary. By charging prisoner's additional room and board, along with the cost of administering the telephone system, when they already have to pay for the calls themselves, prisoners have seen their meagre pay reduced by $30 \%$ in recent years. It should be noted that the most a prisoner can make in a single day is $\$ 6.90$ and that the incentive payments that prisoners previously received for their productive labour at CORCAN have also been eliminated (Comack et al., 2015; Shook, 2015).

It is important to consider the prisoner pay issue as it relates to their ability to maintain contact with their family members and also to take care of other basic needs that are not met by the institution, notwithstanding the supplementation of their diets due to the poor quality and quantity of food. Trevor Bell held in Mission Institution draws this connection by reminding readers of the following:

CSC's mandate is to support our rehabilitation and reintegration into the community. That is simply not possible when an individual now has to choose between calling his community support network, buying deodorant, sending a card to his daughter or going hungry in the evening hours for two weeks.

Often times the public is misinformed of the degree to which prisoners are responsible for the costs of meeting their own needs in federal penitentiaries. In fact, their ability to make purchases for basic goods have been made all the more onerous with the introduction of a new purchasing 
policy brought about as another cost-saving measure (Comack et al., 2015; Shook, 2015). Prisoners like Joe Convict held in Mountain Institution interpret the installation of a one company monopoly as an act of bad-faith on the part of the government, noting "This new privatized purchasing system is based on shear greed and price gouging of one of the poorest demographic in Canadian society".

As can be seen from the above, the pay issue cannot be interpreted as being independent from other issues that prisoners face while incarcerated such as interpersonal violence, thwarted reintegration efforts and barriers to family contact. It is for this reason, perhaps, that almost every response that we received from prisoners made reference to the pay issue either directly or indirectly by mentioning its impact on their lives. One prisoner who responded to our callout reminded us that "It will cost me five cents a page to print this letter and a dollar for the stamp" (Anonymous Prisoner 8 held in Beaver Creek Institution). With the new policy of charging prisoners additional room and board, even at the highest rate of pay available, after deductions, his ten page submission to us actually cost him two days pay for institutional work.

Once again prisoner's calls for change are reasonable: "restore prisoner work pay to where it was before" (Salomonie Jaw held in Beaver Creek Institution). Given that prisoners have not received an increase in wages since the 1980s and the cost of meeting their most basic needs have only ballooned, it would not be unfair for them to also ask for a wage increase (OCI, 2015). Yet the majority of prisoners who wrote to us were simply asking for enough to afford their necessities and maintain contact with their loved ones. The following proposal from Anonymous Prisoner 19 at Drumheller Institution is instructive: "We need better support for our loved ones while we are incarcerated, such as family programs. We need better support for mothers and family that find themselves suddenly alone when we are incarcerated so that they do not have only welfare to get by". Salomonie Jaw held in Beaver Creek Institution echoes this request by simply asking that CSC: "Assist our families and loved ones to visit us, providing an escort so that they will be safe and not get lost during travels".

\section{Old Age Security}

The federal penitentiary population is aging, with approximately one in four prisoners considered to be "seniors" aged 50 and older (OCI, 2015). This is in part due to the large number of prisoners - again, one in four - serving 
indeterminate or life sentences, as well as the increasing number of prisoners sentenced to MMPs that impact those entering the penal system later in life (OCI, 2015; Eliot and Glynes, 2016). This means that the removal of Old Age Security for prisoners by the Harper government has impacted a large proportion of the federal penitentiary population in a negative way:

Even though a person may have been a Canadian born citizen who worked their entire life and paid their taxes, they are now denied the pension funds. I have seen many fellows, whose wives were dependent upon the income to maintain a roof over their head and food on their table, no longer being able to contribute to their family's well-being. They are also no longer able to afford their prescription drugs due to the high cost of same. They have, in some cases, lost their homes and ended-up either on welfare or eating at a soup kitchen post-release. With no funds to establish themselves properly into society, what are their prospects of success and what will be the impact upon their communities?

- Anonymous Prisoner 9 held in Beaver Creek Institution.

There is a strong sense of injustice amongst prisoners who have been dependent upon the funds from Old Age Security to survive on the inside and to support loved ones on the outside. Without this source of income, it is difficult for prisoners to purchase necessities while imprisoned, particularly when they are unable to work institutional jobs. An example of a necessity, for some, would be adult diapers which are no longer provided free of cost, but are instead available for purchase in the catalogue (OCI, 2016). Responses from prisoners also mentioned that the idea of release back to the community scared them, as they no longer had access to funds from OAS to help with their reintegration: "They tell us that we can get our pension back when we get released, but that means those lucky enough to get released, get released with nothing. We have absolutely no way to save anything for anything, let alone release." (David Threinen held in Dorchester Institution). According to their responses, the solution to this problem is evident - reinstate OAS for prisoners.

\section{Education and Vocational Training}

The fact that education and vocational training can have a dramatic impact upon the lives of those who have been criminalized and now find 
themselves within the confines of a penitentiary was also not lost on the prisoners who contacted us. As Anonymous Prisoner 12 held in Beaver Creek Institution notes, "Education and gaining marketable skills are the hallmarks of reduced recidivism". However, as his experience showed, "federal prisoners have little to no access to the Internet and as a result cannot access online post-secondary education programs". While CSC promotes its delivery of interventions that target dynamic risk factors in its stated pursuit of rehabilitation, prisoners themselves recognize this as being only half the battle. Anonymous Prisoner 17 held in Drumheller Institution described this imbalance, echoed by other prisoners who wrote to us, with the following:

I believe that there needs to be a balance between programs to help one become an emotionally balanced person and educational opportunities to become employable. Over the years, CSC's focus seems to be to fix the individual (i.e. their emotional or addictions issues) to the detriment of training for work that will allow them to survive upon release.

To him and other prisoners "this makes no sense" because, in his words, "I can control my emotions, but if I cannot put food on the table, I am put in a position where I may need to turn back to crime to put food on the table, but I will be polite about it!" There seemed to be a particular emphasis placed upon the fact that there is a "lack of educational upgrade opportunities beyond high school equivalence" and prisoners were looking for more meaningful engagement (Anonymous Prisoner 20 held in Mission Institution). While prisoners who wrote to us were aware of the financial pressures and fears of public perception which led to the elimination of the post-secondary education program in 1993, some described even their "attempts at self-education through prisoner paid for correspondence courses are met with extreme administrative red tape and an all-around lack of support" (P.R. held in Mission Institution).

Very much related to prisoner's access to education and vocational training is their access to technology, and in particular computers. Prisoners frequently described the limited avenues available to them to better themselves in this domain. A.C.C.L. held in Beaver Creek Institution who is serving a life sentence reminds us that "Computers are a big part of the outside world and people like myself who have been in since the 1990s do 
not have the experience with email, texts and so on. Computers are used in all places for everything and not knowing anything about them puts us Lifers at a great disadvantage". He, along with several other prisoners, recommend that $\mathrm{CSC}$ revisit their policies around access to technology so that they might better prepare themselves for life in the community.

Given the current state of affairs, many prisoners liken their time in the penitentiary to being warehoused. Without opportunities to better themselves, many prisoners feel as though their being incarcerated is an expensive waste of time. Anonymous at Beaver Creek Institution makes this point noting, "there is such a wasted opportunity for educational training, including post-secondary trades. If offered in a more expansive way, it would make all the difference in the world". To make this difference, some prisoners suggested that penitentiaries be supplanted with "holistic rehabilitation centres, rather than penitentiaries. These centres would revolve around addiction (i.e., alcohol, drugs, psychological, etc.) and preparing prisoners through education and vocational training to reintegrate into society" (1417 held in Riverbend Institution).

\section{Case Management / CSC Staff Culture}

As noted earlier in this paper, CSC made sweeping changes to its case management policy framework (CSC, 2014). These changes, along with a general trend towards a culture of harsh punitiveness found throughout the entire system, have necessarily resulted in a climate where the authority granted to parole officers and other decision-makers in the system has effectively become a form of extra-judicial punishment. One prisoner described his experience with case management as one where they "outright lie, exaggerate, and tailor documents to reflect the narrowest scope and most damning impressions of the prisoner. They have become very skilled in creative writing and delaying tactics - 'sluffing us off"' (Mark Simpson held in Kent Institution). Many authors, in fact, described a poor relationship with their case management team which is not surprising when, as Trevor Bell held in Mission Institution observes:

I have had as many as four different parole officers within a twelve-month period. How is a prisoner supposed to build a working relationship, address their dynamic risk factors and move forward within the system when they are seeing a new face every other week? 
Some prisoners also had concerns about "inaccurate information" being placed on one's file. This could affect important correctional decisions such as one's security classification or whether one is listed as being a member of a security threat group. Given the fact that many prisoners reported an inability to access legal services, challenging inaccurate information on one's file can sometimes be an impossibility as prisoners described the internal grievance system as being broken.

Prisoners also described to us a pattern of "risk averse... decisionmaking" on the part of Institutional Parole Officers and other decision makers in the system (Anonymous Prisoner 8 held in Beaver Creek Institution). A group of Anonymous Prisoners held in Mission Institution described to us an experience of having "little case management outside of timelines" and being in receipt of correctional plans that "lack any reality and teeth in that they act more as a record of ineffective programs", rather than a plan to "move forward into a more productive lifestyle as a contributing member of society, which requires updated programs with accurate facts". Their experience of case-management was depicted as one with "few opportunities to apply goal setting or model the behaviours using the very skills taught in our Integrated Correctional Program Model (ICPM) programs".

Not only have prisoners become especially attuned to the implications of such changes to the CSC Case Management Policy Framework and how this may affect decision-making, but they have become acutely aware of the way that 'law and order' attitudes have become commonplace throughout the entire system. 1417 held in Riverbend Institution captures this with the following statement: "It is not only the confinement, it is the treatment. Guards have a master-slave view of their position. As such their own psyche can make for adversarial conditions". Joe Convict held in Mountain Institution describes this change in attitude as a product of "reverting back to a system of punitive measures, rather than actually encouraging meaningful rehabilitation". He tells us that "One product is that many staff express views on a daily basis that are either demeaning or completely dismissive of pain and suffering" and calls for "significant independent oversight", possibly through the "appointment of a true ombudsman only answerable directly to Parliament and not to the government of the day via the Minister of Public Safety".

Moving forward, prisoners' expectations from their captors are not unrealistic - they simply ask what the system is asking of them, which is to be held accountable for their actions. As Ronald Small held in Mission 
Institution reminds us: "these people signed the Declaration agreeing to undertake and maintain, in the course of their employment, the standards of professionalism and integrity that are therein set forth". Prisoners' calls for professionalism and integrity in corrections are fair requests.

\section{Parole and Conditional Release Conditions}

Parole was a common issue identified by prisoners. The two main changes that prisoners mentioned in their letters were the removal of the accelerated parole review by the Harper government and the extension of the amount of time that Lifers have to wait after being denied parole before applying again, which is now five years.

Anonymous Prisoner 1 held in Grand Valley Institution argues that Accelerated Parole Review (APR) was "a very important law and policy that must be in place to allow certain first-time federal prisoners to re-enter society at one-sixth of their sentences so that they can avoid the damage of incarceration, which undermines community safety". In reference to the change in the eligibility period which an individual must wait before reapplying for parole, Alan Beaulieu of Stony Mountain Institution recognises that this policy shift importunately affects those serving longer sentences and more particularly, Lifers. Under the previous policy, upon reaching their eligibility date for a parole review, if a prisoner was denied, they could re-apply in two years, yet as he describes, under the current policy "you can be warehoused for years. The institutional parole officers often fail to review and update Lifer files for parole review".

Effectively, for many prisoners the above-noted changes in policy have become a de facto lengthening of the portion of their sentences they serve behind bars. These punitive measures also coincided with other changes that restricted prisoners' access to the community in a timely fashion, such as those placed upon access to Unescorted Temporary Absences and Escorted Temporary Absences. For many prisoners, these passes typically serve as stepping stones towards release and offer them an opportunity to experience life in the community, while also building credibility with their case management teams in advance of their parole hearings. Many prisoners who wrote to us now described being caught in a sort of "catch-22" (Anonymous Prisoner 12 held in Beaver Creek Institution). A.C.C.L of Beaver Creek Institution speaks to this dilemma: "I am essentially being barred opportunities to prepare myself for release and the way the system 
is setup for Lifers, it seems that many of us that can safely re-enter the community will be incarcerated beyond their full parole eligibility dates".

In terms of how prisoners are experiencing these changes to parole, they have noticed that they are often persuaded to postpone their parole hearings to a later date by their parole officers. J.D. held in Mission Institution observes:

I have found that in my case, and in most of the prisoners that talk to me about their case, we are being persuaded and pushed to waive our right to apply for parole when we are eligible. I have been told things by IPOs such as "I will not support you for parole unless you wait it out", "I am 99.9\% sure that you will not get parole if you do not waive or postpone your application for parole", and "why are you in such a rush to get out of prison?", at which point I had been in prison for over half of my sentence.

With regards to parole conditions, many prisoners have stated in their contributions that they are often set up to fail with restrictive conditions that are not always related to the offences that they originally committed. For example, William Allan Beaulieu held in Stony Mountain Institution explains: "The various minor parole breaches could be for drinking a bottle of beer, being late for curfew or talking to anyone with some type of conviction or accusation. This social behavior is the norm in a free and democratic society".

Among the solutions to address the issues noted above was to reinstate APR for first-time, non-violent prisoners, which would also ease penitentiary crowding. It was also recommended that "one's [parole] conditions can only include restrictions that are directly related to the offense. For example, if alcohol was not attributed as a cause of an offence then why put a restriction on a parolee that they cannot consume alcohol?" (1417, Riverbend Institution). While others suggested that there should be "alternatives to imprisonment for parole violations when the law is not broken" (Rachel Fayter and Sherry Payne held in Grand Valley Institution). It is argued by prisoners that a more liberal approach towards conditional release and restraint in the use of incarceration as a remedy to minor violations of parole would "facilitate rehabilitation by reducing time spent incarcerated and cutting down on the more than $\$ 100,000$ per year that it takes to house each one of us". 


\section{Pardons}

With sweeping changes made to the eligibility and wait times for which a person in conflict with the law can receive a pardon (see Doob and Webster, 2016), several responses from prisoners indicated the need to reverse reforms enacted under the previous government. Under the old law, individuals seeking to apply for pardon were required to wait three years following warrant expiry of their conviction and sentence for a summary offence and five years following their conviction for an indictable offence (ibid). While in power, the Conservatives nearly doubled these wait times and made certain categories of the criminalized un-pardonable, while at the same time imposing heavy handed user fees of \$631 that make even submitting an application for a pardon unfeasible for some (ibid).

Hyper A'Hern, who is completed an undergraduate degree and was accepted into medical school prior to his offence, notes the impact of not being able to apply for a pardon:

It was originally intended to allow people to not be defined by a single action and provide them with an incentive to work towards making amends by becoming a law-abiding citizen who contributes to society. Today's system is a mockery of those once proud ideals as the Harper government continually tore it apart so that it is nearly impossible to obtain. Many of the criminalized are no longer even potential candidates for a pardon and even if they are, the amount of time it takes to obtain a formal pardon would usually put one well into their golden years. In my situation, I would like to reiterate that not only did I once have grand dreams, but I am not a candidate for pardon. I have a schedule 1 offence with violence and so I am immediately precluded from a candidate position to obtain a pardon. This means that for the rest of my life, the best I can hope to achieve is mediocrity. Where is my incentive to contribute to society? Where is my incentive to not commit an offence again? Do we want a society where an individual is defined by a single action and their only deterrence for not committing harm is prison?

It was also recognised by some prisoners that with changes in technology, accessing information about an individual's past is often only a click away. 1417 held in Riverbend Institution recognised that "in today's world any criminal record against someone will live on forever. There is no 'pulling up 
stakes and restarting' somewhere else as you could have in the pre-internet age". He advocates "that on a first offence that does not include violence and is punished with a sentence of less than five years that no record can be accessed by the media once the warrant has been completed".

Overall, the changes to pardon laws in Canada, described by Hyper A'Hern as "spiteful in nature" and contrary to the "ideals of the Canadian Values", require reform. The path forward that he offers is that the federal government and Canadians "to believe in the redemption of your fellow citizens, and support their efforts to change and become a productive member of their communities". Undertaking a serious examination of the changes brought about by the last government and adjusting the current policy in a manner that is supportive of such efforts seems to be a sensible course of action to take.

\section{CONCLUSION}

At the outset of this Response, we expressed optimism that perhaps Prime Minister Trudeau's professed commitment to "sunny ways" and mandated review of the penal system could lead to meaningful change - change that is desperately needed to calm the storm that has been raging in CSC facilities during the past decade. Recognizing that any attempt at meaningful change behind the walls ought to involve the voices of prisoners who have been weathering this storm and experienced recent penal reforms first hand, we are optimistic that the courageous and eloquent contributions will be received by the federal government as a reasonable forecast for change.

Yet our optimism, like the prisoners who wrote to us, is cautious. Many prisoners, in their letters to us, indicated that they had previously received many letters similar to ours asking for input and saying that their feedback could lead to change. There seemed to be a feeling of despair, as their previous interventions did not lead to the positive changes that they had wished to see. As stated by Daniel W. Threinen, who is chairman of a seniors group at Dorchester Penitentiary:

What really perturbs me about initiatives such as this collection is that a lot is said, but very little seems to come of it. You can publish in whatever journal you wish, but politicians do not read journals. I personally have been in this penitentiary system for 40 plus years without release and have engaged in 
several "studies" of various types concerning incarceration. I have yet to see any of them bare any fruit. But having said that and being the optimist that I am, I must go by the adage, "nothing ventured, nothing gained".

Forging beyond his pessimism, he nonetheless took the time and risk to submit a contribution to this endeavour. It was not lost to us or the prisoners who wrote to us that despite their Charter protected right to freedom of thought, belief, opinion and expression, participating in this exercise could result in retaliation. In fact, many of the prisoners who wrote to us, both opened and closed their letters with expressions that reveal the resiliency of their spirits and a certain optimism in spite of the challenges that they have faced and will continue to face if the government does not act now to address the issues they raised. A.C.C.L. from Beaver Creek Institution captured this with his statement that: "I believe people can change. I believe in rehabilitation and that people are genuinely good. Even as I am surrounded by negativity, constantly pounded, and put down by CSC, I have to believe in what people on the outside and parolees tell me when they say to hang in there, that when I am out things will be different and people are good".

In reflecting upon this project, it should also be recognized that many of the prisoners who wrote to us also began their letters with expressions of accountability for the harms which have brought them to prison in the first place, often putting the burden of responsibility squarely on their own shoulders without reference to the structural factors that have invariably impacted their lives. One prisoner opened his letter to us with the inculpatory statement "To be very clear, my story is not about me decrying the fact I am in prison. I am very guilty and justifiably sentenced as a 'dangerous offender'".

On the whole, the responses that we received from prisoners comprise a comprehensive account of the impacts of the punishment agenda of 2006-2015, including a pragmatic forecast for change moving forward. As facilitators of this collection, we do not claim or endorse every recommendation for change as our own, nor unreflexively accept that every account of penitentiary life found within the margins of these pages can be taken as the impermeable testimony of life behind the wall, as is the case of all accounts of penality, whether produced by captives, captors, academics, the media or anyone else. With this said, that certain issues were repeatedly identified by federal prisoners housed in penitentiaries in all of CSC's five operational regions should speak to the credibility of their words. The voice 
of one person raising an issue can be easily dismissed, but when several people are bringing forward similar concerns engaging in denial ought to be viewed as disingenuous.

It is our hope that our readers, and in particular Prime Minister Justin Trudeau and his Minister of Justice and Attorney General of Canada Jody Wilson-Raybould who was mandated to review criminal justice laws, policies, and practices enacted during the 2006-2015 period under the previous government, will take seriously the voices of prisoners. It is vital that they seriously consider and act upon reasonable calls for change moving forward in numerous areas.

Moreover, it is our hope that the all too often marginalized voices of women, Indigenous, Black, LGBTQ, and elderly prisoners will also be heard, and that their concerns will be meaningfully addressed. It is our belief that despite the fact that many of the challenges which prisoners face in the Canadian carceral state transcend the Harper-era, repealing the laws, policies, and practices introduced from 2006 to 2015 would be a "sunny way" to start the work needed to diminish this country's reliance on incarceration and working towards justice that heals wounds, instead of creating new ones.

\section{REFERENCES}

Arbel, Efrat (2015) “Contesting Unmodulated Deprivation: Sauvé v Canada and the Normative Limits of Punishment", Canadian Journal of Human Rights, 4(1): 121 141.

Comack, Elizabeth, Cara Fabre, and Shanise Burgher (2015) The Impact of the Harper Government's "Tough on Crime" Strategy: Hearing from Frontline Workers, Winnipeg: Canadian Center for Policy Alternatives.

Cook, Alana N. and Ronald Roesch (2012) “"Tough on Crime' Reforms: What Psychology Has to Say About the Recent and Proposed Justice Policy in Canada", Canadian Psychology, 53(3): 217-219.

Correctional Service Canada (2016) Report on Plans and Priorities 2015-2016, Ottawa. Correctional Service Canada (2015) Report on Plans and Priorities 2014-2015, Ottawa. Correctional Service Canada (2014) Report on Plans and Priorities 2013-2014, Ottawa. Correctional Service Canada (2013) Report on Plans and Priorities 2012-2013, Ottawa. Correctional Service Canada (2012) Report on Plans and Priorities 2011-2012, Ottawa.

Chricton, Hayley and Rose Ricciardelli (2016) "Shifting Grounds: Experiences of Canadian Correctional Officers", Criminal Justice Review, 4(1): 427-445.

Doob, Anthony N. and Cheryl M. Webster (2016) "Weathering the Storm? Testing LongStanding Canadian Sentencing in the Twenty-First Century", Crime and Justice, 45(1): 359-418. 
Doob Anthony N. and Cheryl M. Webster (2006) "Countering Punitiveness: Understanding Stability in Canada's Imprisonment Rate”, Law \& Society Review, 40(2): 325-368.

Elliot, Kari G. and Kyle Coady (2016) Mandatory Minimum Penalties in Canada: Analysis and Annotated Bibliography, Ottawa: Department of Justice.

Fine, Sean (2015) "Prisoner Launches Class-Action Suit Over Use of Solitary Confinement", Globe and Mail - July 17.

Fournier-Ruggles, Lynn (2011) "The Cost of Getting Tough on Crime: Isn't Prevention the Policy Answer?", The Journal of Public Policy, Administration and Law, 2(1): 9-28.

Harris, Kathleen (2016) "Prison Watchdog Sees Sharp Decline in Use of Solitary Confinement", CBC News - March 14.

Jackson, Michael. (2015) "Reflections on 40 Years of Advocacy to End the Isolation of Canadian Prisoners", Canadian Journal of Human Rights, 4(1): 57-87.

Jackson, Michael (1983) Prisoners of Isolation: Solitary Confinement in Canada, Toronto: University of Toronto Press.

Jackson, Michael and Graham Stewart (2009) A Flawed Compass: A Human Rights Analysis of the Roadmap to Strengthening Public Safety.

Kerr, Lisa C. (2015) “The Origins of Unlawful Prison Policies”, Canadian Journal of Human Rights, 4(1): 89-119.

Martel, Joane, Renée Brassard and Mylène Jacoud (2011) "When Two Worlds Collide: Aboriginal Risk Management in Canadian Corrections", British Journal of Criminology, 51(2): 235-255.

McElligott, Greg (2009) "The Political Economy of Corrections: Is Canada Ready for Penal Mass Production?”, 81st Annual Conference of the Canadian Political Science Association, May.

Monchalin, Lisa (2016) The Colonial Problem: An Indigenous Perspective on Crime and Injustice in Canada, Toronto: University of Toronto Press.

Monaghan, Jeffrey (2014) "Security Traps and Discourses of Radicalization: Mapping the Surveillance of Muslims in Canada", Surveillance and Society, 12(4): 485-501.

O’Connor, Joe (2015) "'Sunny ways my friends, sunny ways': Lessons of Wilfrid Laurier Not Lost on Trudeau, 120 years later", National Post - October 20.

Office of the Correctional Investigator (2015) Administrative Segregation in Federal Corrections: 10 year trends, Ottawa.

Office of the Correctional Investigator (2016) Annual Report of the Office of the Correctional Investigator 2015-2016, Ottawa.

Office of the Correctional Investigator (2015) Annual Report of the Office of the Correctional Investigator 2014-2015, Ottawa.

Office of the Correctional Investigator (2014) Annual Report of the Office of the Correctional Investigator 2013-2014, Ottawa.

Office of the Correctional Investigator. (2013) Annual Report of the Office of the Correctional Investigator 2012-2013, Ottawa.

Office of the Correctional Investigator. (2012) Annual Report of the Office of the Correctional Investigator 2011-2012, Ottawa.

Paquin-Marseille, Lysiane, Brian A. Grant and Steven Michel (2012) Review of the Prison Crowding and Double-Bunking Literature, Ottawa: Correctional Service Canada. 
Parkes, Debra (2015) "Ending the Isolation: An Introduction to the Special Volume on Human Rights and Solitary Confinement", Canadian Journal of Human Rights, 4(1): vii-xiii.

Parkes, Debra (2014) “The Punishment Agenda in the Courts", Supreme Court Review, 67(2d): 589-615.

Piché, Justin (2015) "Playing the "Treasury Card" to Contest Prison Expansion: Lessons from a Public Criminology Campaign”, Social Justice, 41(3): 145-167.

Piché, Justin and Karine Major (2015) "Prisoner Writing in/on Solitary Confinement: Contributions from the Journal of Prisoners on Prisons, 1988-2013", Canadian Journal of Human Rights, 4(1): 1-33.

Reitano, Julie (2016) Admissions to Adult Correctional Services in Canada, 2015-2016, Ottawa: Statistics Canada.

Ricciardelli, Rose, Hayley Chricton and Lisa Adams (2014) "Stuck: Conditions of Canadian Confinement", Punishment and Incarceration: A Global Perspective, 19: 95-120.

Sampson, Robert, Serge Glascon, Ian Glen, Clarence Louis, and Sharon Rosenfeldt (2007) A Roadmap to Strengthening Public Safety, Ottawa: Minister of Public Works and Government Services.

Shook, Jarrod (2015) "Incentive to Scrutinise", Journal of Prisoners on Prisons, 24(1): 52-54.

Shook, Jarrod (2013) "Debunking Double Bunking in the Correctional Service of Canada: A Critical Qualitative Account", Journal of Prisoners on Prisons, 22(1): 64-67.

Syles, Gresham M. (2007[1958]) The Society of Captives: A Study of a Maximum Security Prison, Princeton: Princeton University Press.

Tonry, Michael (2013) "“Nothing" Works: Sentencing "Reform" in Canada and the United States", Canadian Journal of Criminology and Criminal Justice, 55(4): 465 479.

Trudeau, Justin (2015) Minister of Justice and Attorney General of Canada Mandate Letter, Ottawa: Office of the Prime Minister of Canada.

Union of Canadian Correctional Officers (2011) A Critical Review of the Practice of Double Bunking Within Corrections: The Implications on Staff, Inmates, Correctional Facilities and the Public.

Webster, Cheryl M. and Anthony N. Doob (2015) 'US Punitiveness 'Canadian Style'? Cultural Values and Canadian Punishment Policy”, Punishment \& Society, 17(3): 299-321.

Zinger, Ivan (2016) "Human Rights and Federal Corrections: A Commentary on a Decade of Tough on Crime Policies in Canada", Canadian Journal of Criminology and Criminal Justice, 58(4): 609-627. 